\title{
Relativistically Parametrized Extended-Hückel Calculations. II. Orbital Energies of Group-IV Tetrahalides and Tetramethyls
}

\author{
L. L. LOHR, JR. \\ Department of Chemistry, University of Michigan, Ann Arbor, Michigan 48109 , \\ U.S.A. \\ M. HOTOKKA AND P. PYYKKÖ \\ Department of Physical Chemistry, Abo Akademi, SF-20500 Abo (Turku), Finland
}

\begin{abstract}
Relativistically parametrized extended-Hückel (REX) calculations are reported for $\mathrm{MX}_{4}(\mathrm{M}$ $=\mathrm{Ti}, \mathrm{Zr}, \mathrm{Hf}, \mathrm{C}, \mathrm{Si} . \mathrm{Ge}, \mathrm{Sn}, \mathrm{Pb} ; \mathrm{X}=\mathrm{Cl}, \mathrm{Br}, \mathrm{I})$ and for $\mathrm{M}\left(\mathrm{CH}_{3}\right)_{4}(\mathrm{M}=\mathrm{Ti}, \mathrm{C}, \mathrm{Si}, \mathrm{Ge}, \mathrm{Sn}, \mathrm{Pb})$. Satisfactory agreement is obtained with experiment and with earlier assignments both for the energy levels and for their relativistic splittings. This encourages the use of REX for assigning PES spectra. Double- $\zeta$ radial functions ( $\mathrm{REX}$ and $\mathrm{EHT}$ ) are given for $\mathrm{Cl}, \mathrm{Br}$, and $\mathrm{I}$.
\end{abstract}

\section{Introduction}

Relativistic effects strongly influence the chemical properties of heavier elements $[1,2]$. Perhaps the simplest method, where all the qualitatively different relativistic effects (contractions, expansions, and splittings) can still be included, is provided by the "relativistically parametrized extended Hückel method (REX)" [3-5].

This method is a noniterative one, at the low end of the quality scale. It consists of a single diagonalization of a Hamiltonian matrix, set up using $\left|j m_{j}\right\rangle$ basis orbitals on each atom. Thus the usual EHT basis size is doubled. The diagonal matrix elements $h_{i i}$ are put equal to calculated Dirac-Fock or Hartree-Fock orbital energies in neutral atoms. The off-diagonal ones are obtained from the Wolfsberg-Helmholtz formula. One or more Slater orbitals are used for describing each atomic orbital. In the single-STO case the orbital exponent $\zeta$ can be obtained from the average orbital radius via

$$
\zeta_{i}=\left(n+\frac{1}{2}\right) /\langle r\rangle_{i}
$$

This affords a systematic comparison of the relativistic and nonrelativistic cases, with both the radial and the energetic effects of relativity included. The REX program [5] contains default parameters for the elements 1-120. This parametrization is described in Ref. 4. The program requires only the molecular geometry and yields the relativistic molecular orbitals as a result of the diagonalization. 
We expect that the assignment of photoelectron spectra will form one of the main applications of REX. A rather similar method, incorporating the relativistic splitting but using unsplit radial functions [6], has already been used for this purpose. Two other methods, resembling the present one, have also been proposed $[7,8]$. The experimental PES groups have used simpler means, like an EHT calculation on the $\mathrm{Cl}_{4}$ tetrahedron of $\mathrm{MCl}_{4}(\mathrm{M}=\mathrm{Ti}, \mathrm{Zr}, \mathrm{Hf})$ [9]. The purpose of this paper is to explore these possibilities for halogen and methyl compounds of group-IV metals. We then find that halogen-halogen repulsions are important and demand in some cases a double- $\zeta$ description. The necessary parameters are given in the Appendix.

\section{Group IVa}

Photoelectron spectra for the entire series $\mathrm{MX}_{4}(\mathrm{M}=\mathrm{Ti}, \mathrm{Zr}, \mathrm{Hf} ; \mathrm{X}=\mathrm{Cl}, \mathrm{Br}$, I) were reported by Egdell and Orchard [9]. Their results and assignments are shown as the right-most ones in Figure 1, together with the present EHT and REX ones, obtained using the single- $\zeta$ default parameters $[4,5]$ for the metal and the double- $\zeta$ exponents in the Appendix for the halogens. The bond lengths assumed are shown in Table $\mathbf{I}$.

As seen from Figure 1, the experimental breadths of this "halogen $p$ band" are satisfactorily reproduced. If single- $\zeta$ radial functions would be used for the halogens, the breadth for, e.g., $\mathrm{TiBr}_{4}$ would drop from 2.61 to $1.11 \mathrm{eV}$. The order of orbitals remains unchanged.

Compared to the original assignments, our $e$ and lower $t_{2}$ orbitals are interchanged for $\mathrm{ZrCl}_{4}, \mathrm{TiBr}_{4}, \mathrm{ZrBr}_{4}$, and $\mathrm{HfBr}_{4}$. Otherwise our labels agree with those of Egdell and Orchard [9]. The REX relativistic splittings of the $t_{1}$ HOMO also agree well with the experimental values. Reasonable agreement is found for the $t_{2}$ splittings in the iodides as well. For the upper $t_{2}$ of $\mathrm{HfI}_{4}$, we predict the $\Gamma_{7}$ to lie below the $\Gamma_{8}$ and not vice versa. The $\mathrm{TiCl}_{4}$ LUMO at $-10.32 \mathrm{eV}$ is a $\Gamma_{8}(e)$ having $91 \%$ of its norm in the $3 d$ of $\mathrm{Ti}$.

The REX energy levels of $\mathrm{TiMe}_{4}$ in Table II have the same order and roughly the same spread as the ab initio ones. The $t_{2}$ HOMO of $\mathrm{TiMe}_{4}$ consists of $43 \%$ Ti $3 d$ and $52 \%$ C $2 p$. It exhibits an "inverted spin-orbit splitting" (see Ref. 20), characteristic of $d$ AO:s. Closely under it, the $a_{1}$ MO consists of $88 \% \mathrm{C} 2 p$ and $8 \% \mathrm{Ti} 4 s$. Then follow the $\sigma(\mathrm{C}-\mathrm{H}) t_{1}, t_{2}$, and $e$ bands.

\section{Group IVb}

Photoelectron spectra were reported for the various group-IVb tetrahalides in Refs. 10-13, for the tetramethyls in Refs. 13-15, and for the mixed halomethyls in Ref. 16. Further calculations on these systems appeared in Refs. 17 and 18.

The present results for the halides are shown in Tables III and IV. REX fully supports the earlier assignments, except for $\mathrm{SiBr}_{4}, \mathrm{GeBr}_{4}$, and $\mathrm{SnBr}_{4}$ where it is not quite clear that these assignments are for the $e$ and upper $t_{2}$. Refined ex- 


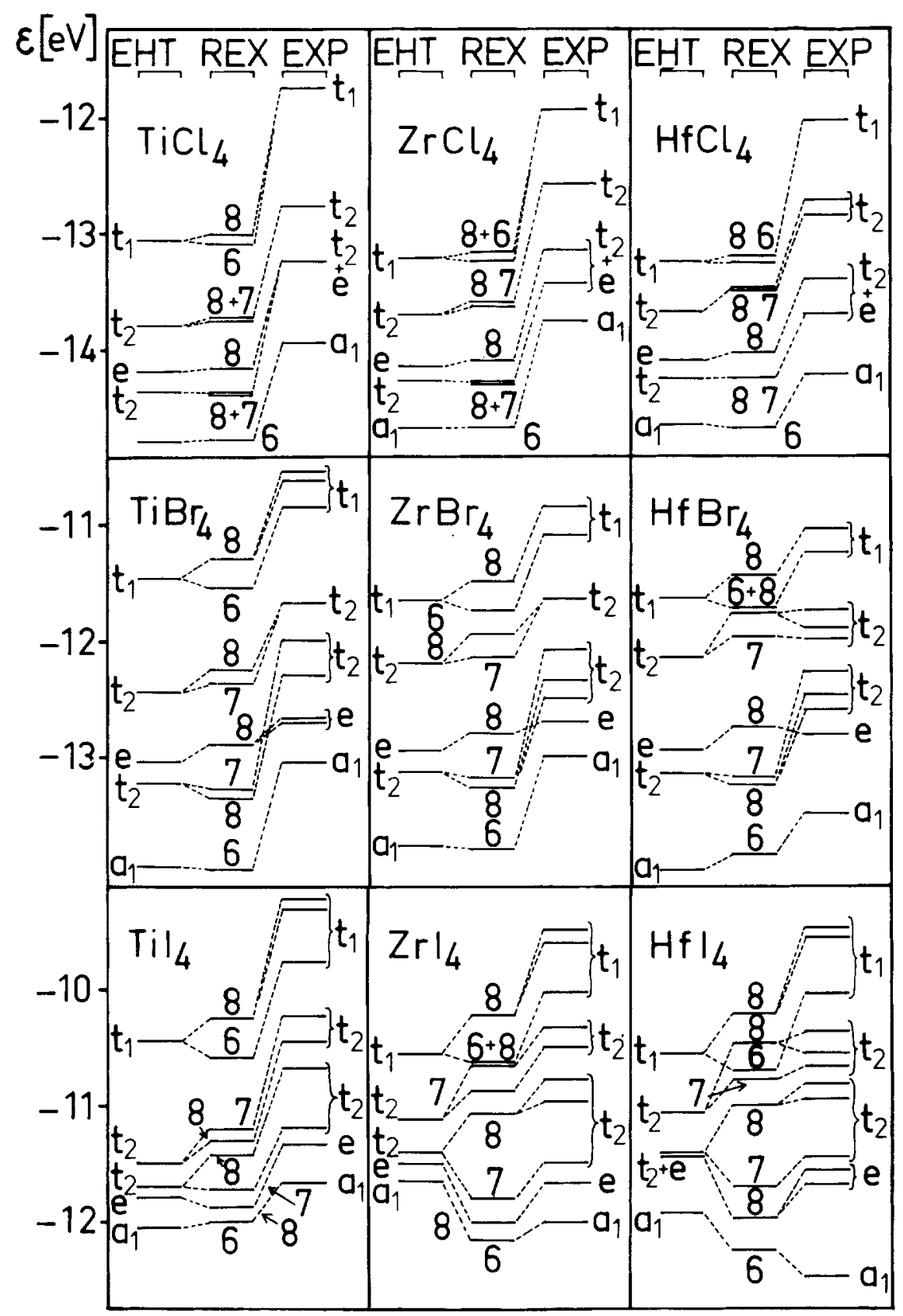

Figure 1. Calculated and experimental (PES) orbital energies [9] for group-IVa halides. For each molecule the EHT, REX, and experimental ones are given from left to right, respectively. In the molecular double-group notation $\Gamma_{6}=e^{\prime}, \Gamma_{7}=e^{\prime \prime}$, and $\Gamma_{8}=u^{\prime}$. 
TABLE I. Halogen-metal and carbon-metal bond lengths, assumed in the calculations (in $\mathrm{pm}$ ).

\begin{tabular}{lllll}
\hline \hline $\mathrm{M}$ & \multicolumn{5}{c}{$\mathrm{X}$} \\
\cline { 2 - 5 } & $\mathrm{C} 1$ & $\mathrm{Br}$ & $\mathrm{I}$ & $-\mathrm{CH}_{3}$ \\
& & & & \\
\hline & & & & \\
$\mathrm{C}$ & 176.6 & 194.2 & 212 & 154.1 \\
$\mathrm{Si}$ & 201.7 & 215 & 243 & 187 \\
$\mathrm{Ge}$ & 211.3 & 229 & 250 & 194.5 \\
$\mathrm{Sn}$ & 227.5 & 244 & 264 & 218 \\
$\mathrm{Ti}$ & 217 & 233.9 & 254.6 & 213 \\
$\mathrm{Zr}$ & 232 & 246.5 & 266 & - \\
$\mathrm{HF}$ & 233 & 245 & 266.2 & - \\
\hline
\end{tabular}

TABLE II. Orbital energies for $\mathrm{TiMe}_{4}$ from REX and from the $a b$ initio calculation [19] (in eV).

\begin{tabular}{llll}
\hline REX & & & Ab initio \\
\hline 7 & 12.36 & $t_{2}$ & 10.78 \\
8 & 12.36 & & \\
6 & 12.57 & $a_{1}$ & 11.22 \\
8 & 14.61 & $t_{1}$ & 14.29 \\
6 & 14.61 & & \\
8 & 15.20 & $t_{2}$ & 14.94 \\
7 & 15.20 & & \\
8 & 15.35 & $\mathrm{e}$ & 15.18 \\
\hline Spread 2.99 & & 4.40 \\
\hline
\end{tabular}

periments would be desirable on these systems and also on $\mathrm{Cl}_{4}$ and $\mathrm{SiI}_{4}$. A particularly satisfying case are the iodides of $\mathrm{Ge}$ and $\mathrm{Sn}$, where the original assignments were done in double-group notation. The NEVE spin-orbit splittings [18] in Table IV also are in reasonable agreement with the present ones. 
in $\infty$

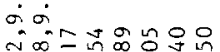

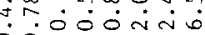

$\infty \infty \infty \sim \sim \infty$.

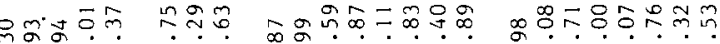

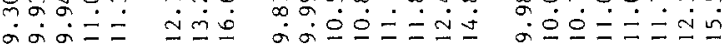

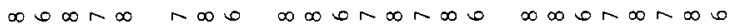

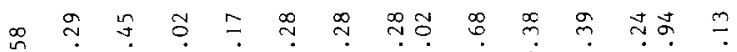

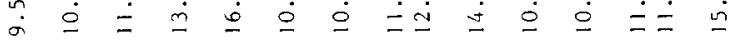

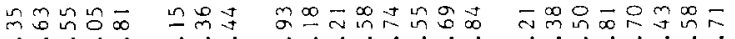

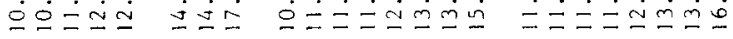

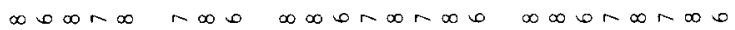

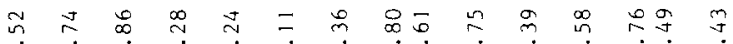

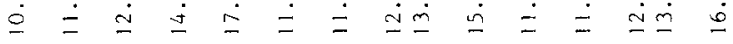

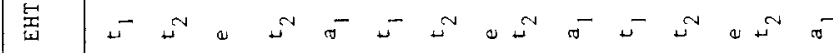

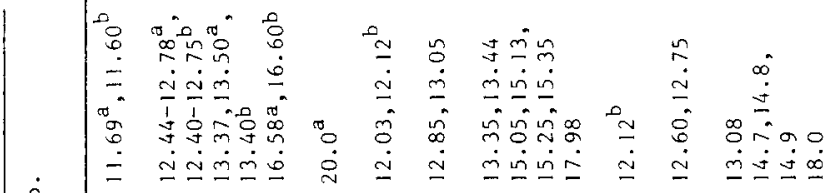


TABLE IV. Orbital energies of tin halides $\mathrm{SnX}_{4}$ (in eV).

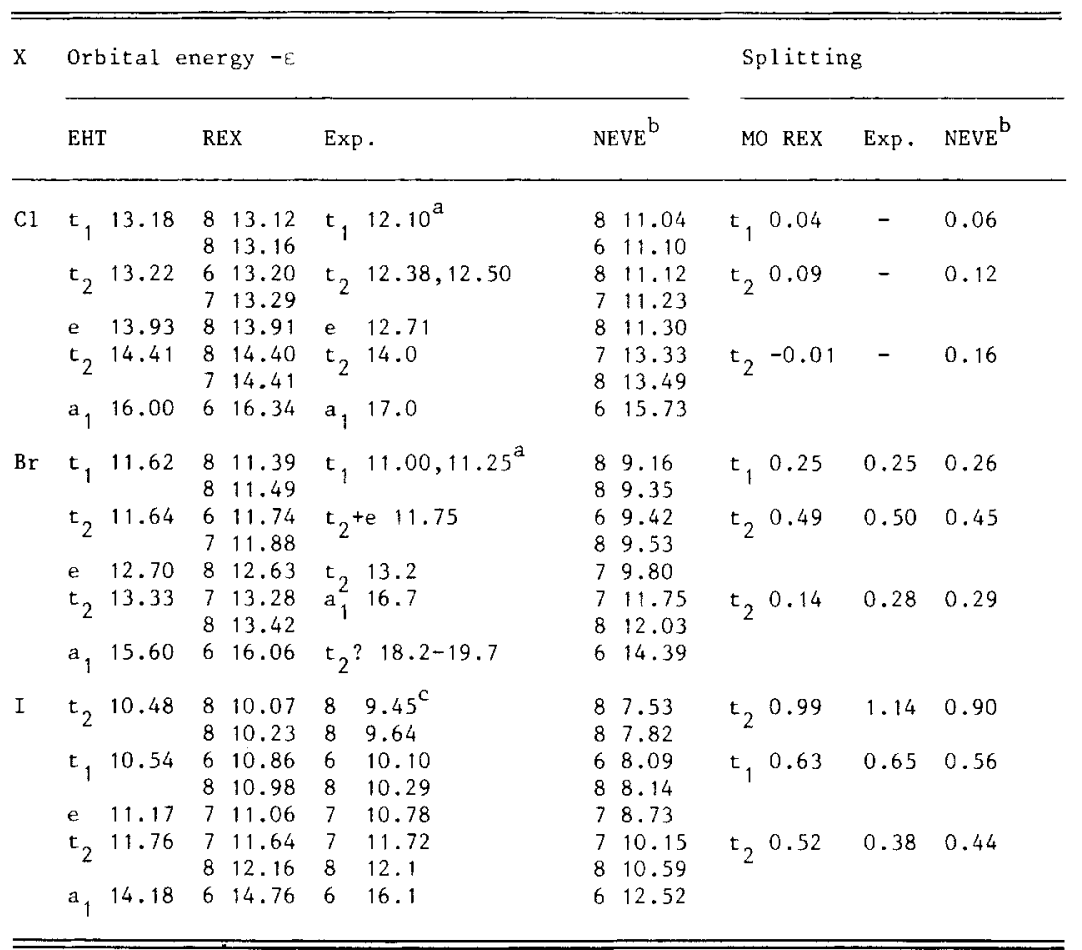

a Green et al. [11].

${ }^{b}$ Hyde and Peel [18].

c Burroughs et al. [12].

The calculated and observed orbital energies of the tetramethyls are compared in Table $\mathrm{V}$. We first note that, in agreement with the experimental assignments $[13,15]$, the PES spectrum can be divided into three bands, $A$ : the $\mathrm{M}-\mathrm{C} t_{2}$ HOMO, $B$ : a broad $\sigma(\mathrm{C}-\mathrm{H})$ band, and $C$ : an $\mathrm{M}-\mathrm{C} a_{1}$ at the bottom of the spectrum. For $\mathrm{PbMe}_{4}$, the $A$ band suffers a relativistic splitting of $0.91 \mathrm{eV}$ [15] or $0.65 \mathrm{eV}$ [13]. We find a somewhat smaller splitting of $0.46 \mathrm{eV}$, probably because the noniterative REX pulls off too much charge from $\mathrm{Pb}$ to the carbons, giving too little $\mathrm{Pb} 6 p$ character to the $t_{2}$ HOMO. For $\mathrm{SnMe}_{4}$ the splitting, predicted to be $0.13 \mathrm{eV}$, was not observed [13,15]. For $\mathrm{SnMe}_{4}$ the REX calculation predicts that band $C$ merges into band $B$, providing a natural explanation that it was not experimentally seen in Ref. 15 . In Ref. 13 the structure seen at 14.8 $\mathrm{eV}$ might correspond to this $a_{1}$ MO. The EHT band $C$ for $\mathrm{PbMe}_{4}$ would also merge into band $B$ but the relativistic contraction of the $6 s$ AO in REX again pulls it down.

The detailed structure of the $B$ band was only experimentally resolved for neopentane. The present calculations disagree with the presumably more reliable 
TABLE V. Calculated and observed orbital energies for the tetramethyls $\mathrm{MMe}_{4}(\mathrm{M}=\mathrm{C}, \mathrm{Si}, \mathrm{Ge}, \mathrm{Sn}$, and $\mathrm{Pb})$. Symbols $A-C$ for the bands are explained in the text and in Ref. 15.

\begin{tabular}{|c|c|c|c|c|}
\hline \multirow[t]{2}{*}{ M } & \multicolumn{4}{|c|}{ Orbital energy $-\mathrm{e}(\mathrm{eV})$} \\
\hline & REX & & Exp. & \\
\hline \multirow[t]{3}{*}{ C } & ${ }_{7}^{8}\left(t_{2}\right)$ & $\begin{array}{l}12.36 \\
12.37\end{array}$ & ${ }^{t}{ }_{2} \frac{10.89,}{10.96,11.39,},_{b} 11.86^{3}$ & (A) \\
\hline & $\begin{array}{ll}8 & \left(t_{1}\right) \\
6 & \\
8 & \left(t_{2}\right) \\
7 & \left(t^{2}\right) \\
8 & (e)\end{array}$ & $\begin{array}{l}13.26 \\
13.26 \\
15.54 \\
15.54 \\
15.92\end{array}$ & 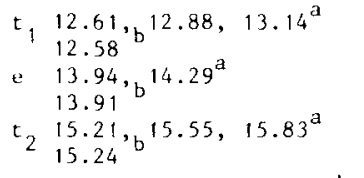 & (B) \\
\hline & $6\left(a_{1}\right)$ & 17.95 & $a_{1} 17.77^{a}, 17.68-18.34^{b}$ & (c) \\
\hline \multirow[t]{3}{*}{$\mathrm{Si}$} & ${ }_{7}^{8}\left(t_{2}\right)$ & $\begin{array}{l}11.55 \\
11.56\end{array}$ & $\mathrm{t}_{2}{ }_{10.57}^{10.29} \mathrm{~b}^{10.62,10.9^{\mathrm{a}}}$ & (A) \\
\hline & $\begin{array}{l}8 \\
6\left(t_{1}\right) \\
8 \\
7\left(t_{2}\right) \\
8(e)\end{array}$ & $\begin{array}{l}14.24 \\
14.25 \\
15.28 \\
15.28 \\
15.51\end{array}$ & 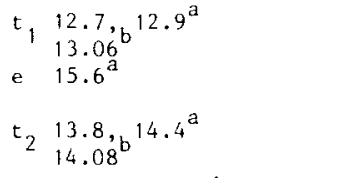 & (B) \\
\hline & $6\left(a_{1}\right)$ & 15.98 & $a_{1} 14.5^{a}, 15.58^{b}$ & (c) \\
\hline \multirow[t]{3}{*}{ Ge } & $\frac{8}{7}\left(t_{2}\right)$ & $\begin{array}{l}11.61 \\
11.68\end{array}$ & 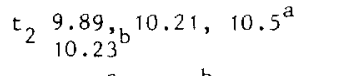 & (A) \\
\hline & $\begin{array}{l}8 \\
6 \\
8 \\
8 \\
7\left(t_{1}\right) \\
8\left(t_{2}\right) \\
8(e)\end{array}$ & $\begin{array}{l}14.37 \\
14.38 \\
15.24 \\
15.24 \\
15.43\end{array}$ & $\begin{array}{l}t_{1} 13.0^{\mathrm{a}}, 13.0^{\mathrm{b}} \\
\text { e } 15.8^{\mathrm{a}} \\
\mathrm{t}_{2} 14.0^{\mathrm{a}}, 13.85^{\mathrm{b}}\end{array}$ & (B) \\
\hline & $6\left(a_{1}\right)$ & 16.48 & $a_{1} 14.0^{a}, 15.9^{b}$ & (c) \\
\hline \multirow[t]{3}{*}{ sn } & $7_{7}^{8}\left(t_{2}\right)$ & $\begin{array}{l}11.61 \\
11.75\end{array}$ & $\mathrm{t}_{2} \frac{9.36, b^{9.70}}{9.65,9.85^{a}}$ & (A) \\
\hline & 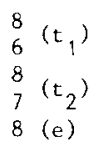 & $\begin{array}{l}14.65 \\
14.66 \\
15.14 \\
15.15 \\
15.24\end{array}$ & $\begin{array}{l}\mathrm{t}_{1} 13.0^{\mathrm{a}}, 13.4^{\mathrm{b}} \\
\text { e } 14.8^{\mathrm{a}} \\
\mathrm{t}_{2} 13.8^{\mathrm{a}}\end{array}$ & (B) \\
\hline & $6\left(a_{1}\right)$ & 15.61 & $a_{1} 12.1^{a}$ & (c) \\
\hline \multirow[t]{3}{*}{$\mathrm{Pb}$} & ${ }_{7}^{8}\left(\mathrm{t}_{2}\right)$ & $\begin{array}{l}11.45 \\
11.91\end{array}$ & ${ }^{\mathrm{t}}{ }_{2} \begin{array}{l}9.10,9.75^{\mathrm{a}} \\
8.81-9.86^{\mathrm{b}}\end{array}$ & (A) \\
\hline & 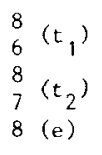 & $\begin{array}{l}14.70 \\
14.71 \\
15.12 \\
15.14 \\
15.20\end{array}$ & $\begin{array}{l}t_{1} 12.96, b^{13.1^{a}} \\
\text { e } 13.3 .0,15.2^{a}\end{array}$ & (B) \\
\hline & $6\left(a_{1}\right)$ & 16.50 & $a_{1} 11.5^{a}, 15.3^{b}$ & (C) \\
\hline
\end{tabular}

a Jones et al. [13].

${ }^{b}$ Evans et al. [15]. 


\section{IODINE $5 P^{*}$ ORBITAL}

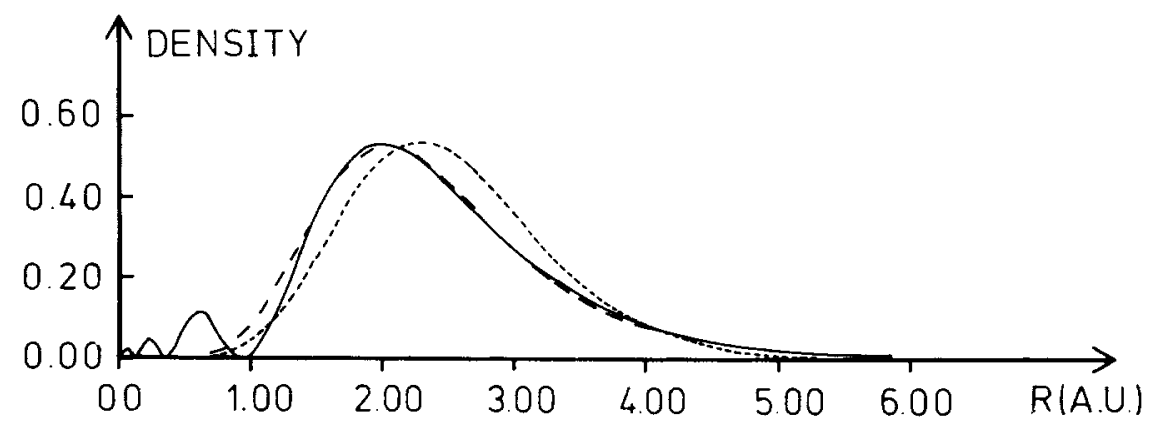

Figure 2. Dirac-Fock radial electron density for the $5 p_{1 / 2} \mathrm{AO}$ of neutral iodine (-) and a double- $\zeta$ fit to it $(---)$. Fit to various expectation values $\left\langle\boldsymbol{r}^{n}\right\rangle$ (see text) is also shown (--).

TABLE V1. Double- $\zeta$ radial functions for $\mathrm{Cl}, \mathrm{Br}$, and $\mathrm{I}$.

\begin{tabular}{|c|c|c|c|c|c|}
\hline Case & AO & $c_{1}$ & $\zeta_{1}$ & ${ }^{c_{2}}{ }_{2}$ & $\zeta_{2}$ \\
\hline$C l(n \cdot r)$. & $\begin{array}{l}3 s \\
3 p\end{array}$ & $\begin{array}{l}0.999682 \\
0.919820\end{array}$ & $\begin{array}{l}2.25842 \\
2.05909\end{array}$ & $\begin{array}{l}0.012665 \\
0.146813\end{array}$ & $\begin{array}{l}2.25842 \\
0.775109\end{array}$ \\
\hline $\mathrm{Cl}$ (rel.) & $\begin{array}{l}3 s \\
3 p^{*} \\
3 p\end{array}$ & $\begin{array}{l}0.999697 \\
0.919490 \\
0.918358\end{array}$ & $\begin{array}{l}2.26709 \\
2.06710 \\
2.05843\end{array}$ & $\begin{array}{l}0.012394 \\
0.149084 \\
0.149436\end{array}$ & $\begin{array}{l}2.26709 \\
0.773385 \\
0.776501\end{array}$ \\
\hline $\mathrm{Br}(\mathrm{n}, \mathrm{r} \cdot)$ & $\begin{array}{l}4 \mathrm{~s} \\
4 \mathrm{p}\end{array}$ & $\begin{array}{l}0.984626 \\
0.836835\end{array}$ & $\begin{array}{l}2.65277 \\
2.42481\end{array}$ & $\begin{array}{l}0.012664 \\
0.277220\end{array}$ & $\begin{array}{l}0.525888 \\
1.09979\end{array}$ \\
\hline Br(rel.) & $\begin{array}{l}4 \mathrm{~s} \\
4 \mathrm{p} \\
4 \mathrm{p}\end{array}$ & $\begin{array}{l}0.983296 \\
0.840782 \\
0.831212\end{array}$ & $\begin{array}{l}2.70069 \\
2.46529 \\
2.42750\end{array}$ & $\begin{array}{l}0.019014 \\
0.283303 \\
0.286533\end{array}$ & $\begin{array}{l}0.596134 \\
1.08780 \\
1.10022\end{array}$ \\
\hline$I(n \cdot r)$. & $\begin{array}{l}5 s \\
5 p\end{array}$ & $\begin{array}{l}0.949378 \\
0.745168\end{array}$ & $\begin{array}{l}2.72014 \\
2.54251\end{array}$ & $\begin{array}{l}0.063054 \\
0.311936\end{array}$ & $\begin{array}{l}1.31258 \\
1.51109\end{array}$ \\
\hline $\mathrm{I}(\mathrm{rel})$. & $\begin{array}{l}5 \mathrm{~s} \\
5 \mathrm{p}^{*} \\
5 \mathrm{p}\end{array}$ & $\begin{array}{l}0.947035 \\
0.777557 \\
0.731350\end{array}$ & $\begin{array}{l}2.83202 \\
2.62109 \\
2.55534\end{array}$ & $\begin{array}{l}0.079050 \\
0.293935 \\
0.331125\end{array}$ & $\begin{array}{l}1.27504 \\
1.46964 \\
1.50492\end{array}$ \\
\hline
\end{tabular}

CNDO/2, SCCMO, and MINDO ones in Ref. 13 by putting the $t_{1}, t_{2}$, and $e$ levels in the order given in Table $\mathrm{V}$.

\section{Conclusion}

The present results, both for the nonrelativistic levels and for their relativistic shifts and splittings, encourage further applications of REX on the assignment of photoelectron spectra. 


\section{Appendix: Double- $\zeta$ Functions for $\mathrm{Cl}, \mathrm{Br}$, and I}

Two different ways were tried for obtaining the fit.

(1) A least-squares fit to the radial expectation values $r_{\max },\langle r\rangle,\left\langle r^{2}\right\rangle,\left\langle r^{4}\right\rangle$, and $\left\langle r^{6}\right\rangle$.

(2) A direct least-squares fit to the radial electron density $P^{2}+Q^{2}$ at the tabulation points of an average-of-configuration Dirac-Fock calculation on the neutral halogen atom.

As seen from Figure 2 for the $5 p_{1 / 2}$ AO of iodine, method 2 gives a better fit to the original density, in addition to being more stable numerically, both for $\mathrm{Cl}, \mathrm{Br}$, and $\mathrm{I}$. Therefore it was chosen for the final parameters given in Table VI.

\section{Bibliography}

[1] P. Pyykkö, Adv. Quantum Chem. 11, 353 (1978).

[2] P. Pyykkö and J. P. Desclaux, Acc. Chem. Res. 12, 276 (1979).

[3] L. L. Lohr, Jr. and P. Pyykkö, Chem. Phys. Lett. 62, 333 (1979).

[4] P. Pyykkö and L. L. Lohr, Jr., to be published.

[5] L. L. Lohr, Jr., M. Hotokka, and P. Pyykkö, Quantum Chemistry Program Exchange, 12, $387(1980)$.

[6] R. Manne, K. Wittel, and B. S. Mohanty, Mol. Phys. 29, 485 (1975).

[7] E. A. Boudreaux, T. P. Carsey, A. Dutta-Ahmed, E. S. Elder, and L. E. Harris, Abstr. EUCHEM Conf. on Electr. Str. of Trans. Met. Compl., Maynooth, Ireland (1978).

[8] I. B. Bersuker, S. S. Budnikov, and B. A. Leizerov, Int. J. Quantum Chem. 11, 543 (1977).

[9] R. G. Egdell and A. F. Orchard, J. Chem. Soc. Faraday Il 74, 485 (1978).

[10] A. W. Potts, H. J. Lempka, D. G. Streets, and W. C. Price, Phil. Trans. R. Soc. Lond. Sec. A 268,59(1970).

(11] J. C. Green, M. L. H. Green, P. J. Joachim. A. F. Orchard, and D. W. Turner, Phil. Trans. R. Soc. Lond. Sec. A 268, 111 (1970).

[12] P. Burroughs, S. Evans, A. Hamnett, A. F. Orchard, and N. V. Richardson, J Chem. Soc. Faraday II 70, 1895 (1974).

[13] A. E. Jonas, G. K. Schweitzer, F. A. Grimm, and T. A. Carlson, J. Electron Spectrosc. Relat. Phenom. 1, 29 (1972/73).

[14] T. A. Carlson, G. E. McGuire, A. E. Jonas, K. L. Cheng, C. P. Anderson, C. C. Lu, and B. P. Pullen, in Electron Spectroscopy. D. A. Shirley, Ed. (North-Holland, Amsterdam, 1972), p. 207.

[15] S. Evans, J. C. Green, P. J. Joachim, A. F. Orchard, D. W. Turner, and J. P. Maier, J. Chem. Soc. Faraday 11 68, 905 (1972).

[16] A. Flamini, E. Semprini, F. Stefani, S. Sorriso, and G. Cardaci, J. Chem. Soc. Dalton 731 (1976).

[17] R. N. Dixon, J. N. Murrell, and B. Narayan, Mol. Phys. 20,611 (1971).

[18] R. G. Hyde and J. B. Peel, Mol. Phys. 33, 887 (1977).

[19] M. Hotokka and P. Pyykkö, J. Organomet. Chem. 174, 289 (1979).

[20] P. Pyykkö and J. P. Desclaux, Chem. Phys. Lett. 50, 503 (1977).

Received February 7, 1980 